\title{
Initial Investigation of Reaction Control System Design on Spacecraft Handling Qualities for Earth Orbit Docking
}

\author{
Randall E. Bailey ${ }^{1}$ E. Bruce Jackson, ${ }^{2}$ and Kenneth H. Goodrich ${ }^{3}$ \\ NASA Langley Research Center, Hampton, Virginia, 23681 \\ W. Al Ragsdale ${ }^{4}$, and Jason Neuhaus ${ }^{5}$ \\ Unisys Corporation, Hampton, VA, 23681 \\ and \\ Jim Barnes ${ }^{6}$ \\ ARINC, Hampton, VA, 23666
}

\begin{abstract}
A program of research, development, test, and evaluation is planned for the development of Spacecraft Handling Qualities guidelines. In this first experiment, the effects of Reaction Control System design characteristics and rotational control laws were evaluated during simulated proximity operations and docking. Also, the influence of piloting demands resulting from varying closure rates was assessed. The pilot-in-the-loop simulation results showed that significantly different spacecraft handling qualities result from the design of the Reaction Control System. In particular, cross-coupling between translational and rotational motions significantly affected handling qualities as reflected by Cooper-Harper pilot ratings and pilot workload, as reflected by Task-Load Index ratings. This influence is masked - but only slightly - by the rotational control system mode. While rotational control augmentation using Rate Command Attitude Hold can reduce the workload (principally, physical workload) created by cross-coupling, the handling qualities are not significantly improved. The attitude and rate deadbands of the RCAH introduced significant mental workload and control compensation to evaluate when deadband firings would occur, assess their impact on docking performance, and apply control inputs to mitigate that impact.
\end{abstract}

\section{Introduction}

Handling qualities embody "those qualities or characteristics of an aircraft that govern the ease and precision with which a pilot is able to perform the tasks required in support of an aircraft role."1 These same qualities are as critical, if not more so, in the operation of spacecraft.

Handling qualities includes more than just stability and control characteristics of a spacecraft or aircraft. Handling qualities are affected by all aspects of the "pilot-vehicle dynamic system," shown in Fig. $1 .^{2}$ The pilot serves as the system controller, driven by a piloting task or objective, using motion, visual and aural cues of the vehicle response, as well as any feedback from the controller force-feel. The pilot's role is delineated as "the decision-maker of what is to be done, the comparator of what's happening versus what he wants to happen, and the supplier of corrective inputs to the aircraft controls to achieve what he desires."

The National Aeronautics and Space Administration (NASA) has initiated a multi-centered Spacecraft Handling Qualities project. This project will provide invaluable data and guidelines for the design, development, test, and evaluation of NASA's Constellation Program platforms as well as all future NASA and other government agency

${ }^{1}$ Aerospace Technologist, Crew Systems and Aviation Operations Branch, Mail Stop 152.

${ }^{2}$ Aerospace Technologist, Dynamic Systems and Guidance Branch, Mail Stop 308, AIAA Associate Fellow

${ }^{3}$ Aerospace Technologist, Dynamic Systems and Guidance Branch, Mail Stop 308, AIAA Senior Member

${ }^{4}$ Aerospace Engineer, Simulation Development and Analysis Branch, Mail Stop 169, AIAA Associate Fellow

${ }^{5}$ Aerospace/Software Engineer, Simulation Development and Analysis Branch, Mail Stop 169, Senior Member

${ }^{6}$ Aerospace/Software Engineer, Simulation Development and Analysis Branch, Mail Stop 169 
and commercial spacecraft. A research, development, test, and evaluation process is in effect to identify, understand, and interpret the engineering and human factors principles which govern the pilot-vehicle dynamic system as they pertain to space exploration missions and tasks.

In this paper, the results of an initial investigation of Reaction Control System (RCS) design characteristics on Spacecraft Handling Qualities during Earth Orbit Docking are described.

A pilot-in-the-loop simulation was conducted for the spacecraft proximity operations and docking task. Experimental variations were used to assess the influence of the following primary variables on spacecraft handling qualities:

- RCS design characteristics and rotational control law modes.

- Docking task initial condition and closure rate.

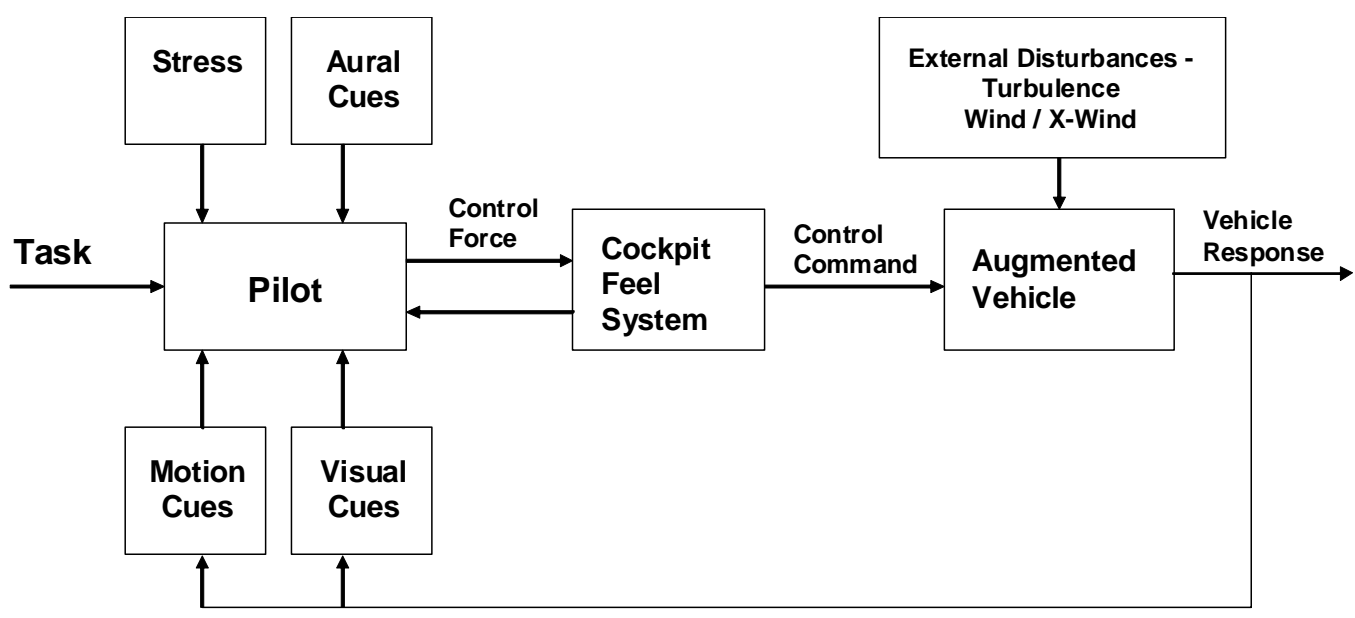

Figure 1: Pilot-Vehicle Dynamic System

\section{Background}

The Orion Crew Exploration Vehicle (CEV) is being developed to perform Rendezvous, Proximity Operations and Docking (RPOD) in low Earth as well as in low lunar orbit. ${ }^{3}$ The vehicle is being designed for RPOD with the International Space Station (ISS), the Lunar Landing Vehicle, and the Earth Departure stage. Numerous challenges are associated with these and other program requirements, driving RCS designs. For instance, as detailed in Reference 4, trade study assessments of various RCS designs were conducted for: a) authority and precision of control; b) robustness and efficiency; and, c) plume impingement. Control authority and precision was assessed analytically against program requirements. A skewed and canted RCS thruster orientation was down-selected (see Fig. 2, extracted from Reference 4). However, pilot-in-the-loop simulation and handling qualities assessments of the various configurations were not included in the trade study.

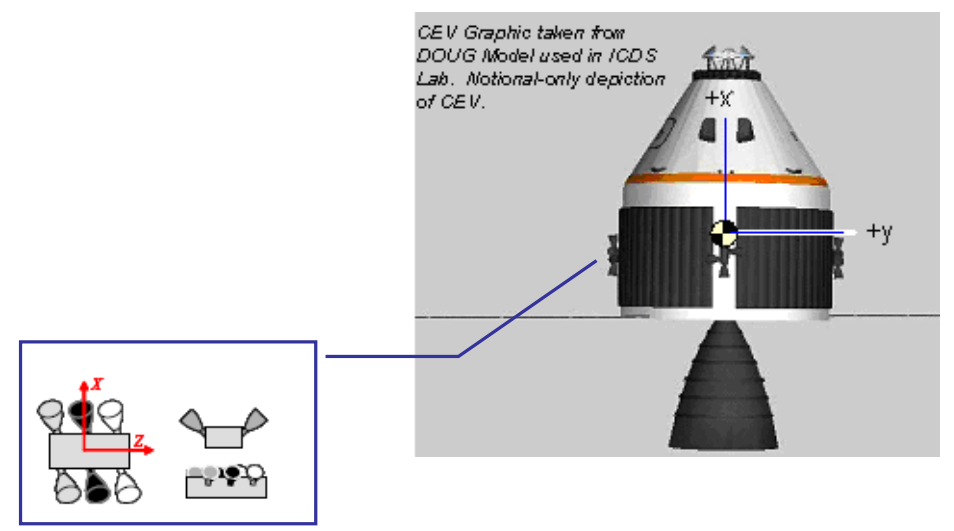

Figure 2. Notional CEV RCS Design (Reference 4) 
While much of the Orion vehicle and its guidance, control, and navigation subsystems are designed to accommodate automated or autonomous RPOD, requirements for Orion also dictate manual control for RPOD. Since RPOD operations are critical functions required for crew survival and mission success, manual control will improve the probabilities for a successful outcome in the event that automated functions are unable to perform the maneuvers. Time and time again, history shows that human control of operations is much more robust to system uncertainties, malfunctions, failures, or unexpected events than automated systems. Further, a satisfactory design of a manual control mode for RPOD will improve confidence in achieving a successful and safe docking with the target under automated control and is required for human rating of the Orion and its overall mission success.

During Gemini and Apollo, significant research was conducted, not only for the development of the guidance, navigation, and control requirements for RPOD, but also in the parametric investigation of what drives the handling qualities for successfully docking two vehicles in space. This work investigated the handling qualities influence of such parameters as:

- Spacecraft attitude control mode, control power, target lighting and target oscillatory motion;,

- $\quad$ "Remote" docking using closed-circuit television; ${ }^{7}$

- Visual aides, in day and night conditions, to align to a docking target ${ }^{8}$

- Hand controllers, instruments, and control modes; ${ }^{9}$

- Visual simulation compared to "full-size" docking; ${ }^{10}$

- Visual aides and attitude control modes in lunar orbit. ${ }^{11}$

These studies provided a wealth of data from which to begin the development of Spacecraft Handling qualities guidelines. Unfortunately, application of these works to modern systems suffers in two critical aspects: 1) the handling qualities data used the Cooper rating scale, ${ }^{12}$ not the Cooper-Harper pilot rating scale ${ }^{1}$ which is today's accepted standard; and, 2) analog simulations were conducted; hence, critical digital flight control system effects and control law techniques were not evaluated.

These parametric evaluations established the state-of-the-art at that time and immeasurably helped in creating the extremely successful Gemini and Apollo docking capabilities and designs. So much so, in fact, that as the Space Shuttle was being developed, RPOD was assumed to be a lower priority in the early days of the program (i.e., it had less technical risk) compared to other system development tasks. ${ }^{13}$ It wasn't until later in the program that the unique attributes of the Shuttle design for RPOD were recognized, resulting in "complex operational work-arounds over the life of the program"13 that might have otherwise been mitigated earlier in the Shuttle design by continued parametric evaluation of handling qualities requirements.

As NASA embarks on the Constellation program, the development of a well-founded basis for Spacecraft Handling Qualities is being put in place. The Spacecraft Handling Qualities program should provide invaluable parametric data for the design of the Constellation vehicles and, just as importantly, establish guidelines for future vehicles as well to enable more cost effective and efficient operations. Additional beneficiaries of these handling qualities guidelines may include NASA's recent efforts to stimulate the private sector into providing commercial access to space in the form of the Commercial Orbital Transportation Services (COTS) program.

\section{Test Description}

Pilot-in-the-loop simulation was conducted by employing "generic" spacecraft models to span a parametric space for the development of spacecraft handling qualities. These test points also span Orion/Constellation pointspecific design issues and concepts to assist in trade-study parametrics.

\section{A. Simulated Spacecraft}

To evaluate RCS design effects, two different spacecraft models were used. The first model (the so-called "generic" spacecraft), shown conceptually in Fig. 3, used a ring of 4 RCS thruster pods, each containing 4 orthogonally-directed jets for translation and rotation. This jet arrangement loosely mirrors Apollo and Gemini-era designs. Using this model, parametric variations for handling qualities were easily simulated because of the orthogonal direction of the RCS jets. For this test, the RCS jet location was experimentally varied while the centerof-gravity (CG) and the location of the pilot and docking port with respect to the CG was held constant.

The second spacecraft model conceptually followed a skewed-canted RCS design analogous to that shown in Fig. 2. This model (the so-called "ARC-CEV" model) was employed in the companion Ames Research Center (ARC) spacecraft handling qualities test. ${ }^{14}$ Because of the RCS design, coupling effects were significant. 


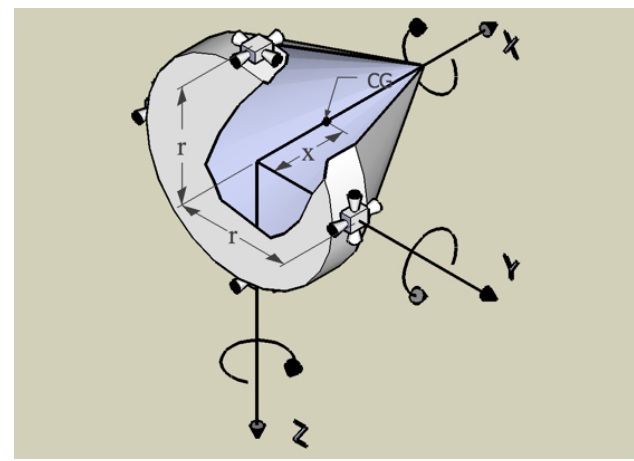

Figure 3 LaRC Generic Spacecraft Model

\section{B. Simulator}

The experiment was conducted in the Research Flight Deck ${ }^{15}$ simulation facility at NASA Langley Research Center (LaRC). The Research Flight Deck employs a large field-of-view, out-the-window collimated visual system. The simulator nominally emulates a two-person, side-by-side transport aircraft cockpit but was modified to simulate a spacecraft pilot station. For both models, the center-of-gravity was located $3.67 \mathrm{ft}$ aft, $1.5 \mathrm{ft}$ left, and $4.275 \mathrm{ft}$ below the design eye reference in the simulation.

The right-hand pilot station was modified by the addition of an Apollo-vintage Rotational Hand Controller (RHC) and a Translational Hand Controller (THC). The controllers (Fig. 4) were mechanical and their characteristics fixed. The THC provided 3-axis translational control commands (in/out: fore/aft translation; up/down: vertical translation; and left/right: lateral translation). The RHC provided 3-axis rotational control commands, using a base pivot for roll, palm-pivot for pitch, and twist-pivot for yaw.

The out-the-window visual scene showed the ISS and cockpit masking was used to approximate a notional spacecraft window. The window placement and orientation nominally allowed viewing of the ISS docking port from the design eye position until within $5 \mathrm{ft}$ of docking.
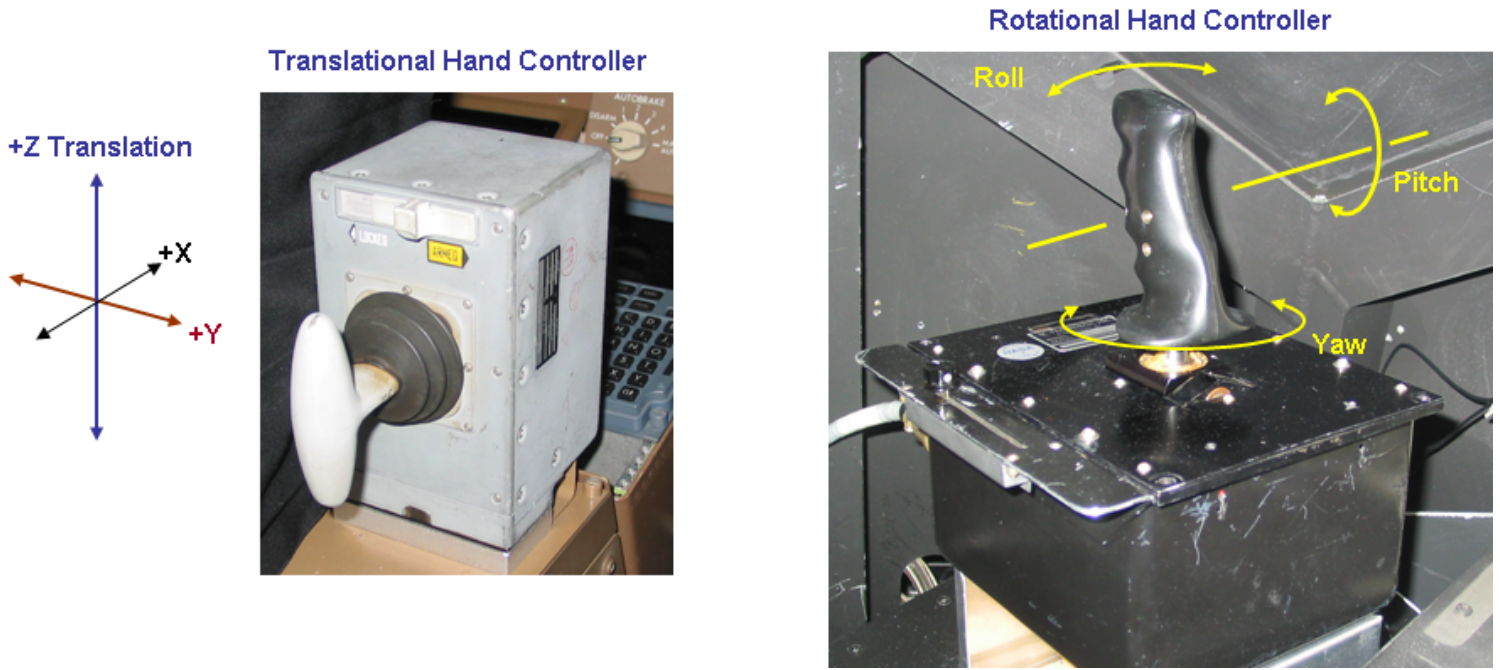

Figure 4. Translational and Rotational Hand Controllers

Aural call-outs of the range of the ownship docking port from the ISS docking port was provided to the Evaluation Pilot (EP). The call-out values were at 40,30, 20, 15, and $10 \mathrm{ft}$ followed by each foot thereafter until docking. The call-outs were used to replicate the cues which would be expected under crew resource management principles as per current shuttle operations standard operating procedures. ${ }^{16}$ 


\section{Head-Down Displays}

Three 8" x 8" color multi-function displays were installed on the forward instrument panel. These displays showed a Rendezvous and Proximity Operations Program (RPOP)-type display, an Attitude Direction Indicator (ADI), and a Centerline Camera display.

The RPOP-type display mimicked the RPOP display currently in use during Shuttle operations. ${ }^{17}$ This display provides digital read-outs of the vehicle's current position and rates (referenced to the docking port position) with respect to a local vertical/local horizontal (LVLH) reference frame located at the ISS docking port position. The RPOP also showed a side view of the vehicles current and past positions with respect to the ISS docking port. The side view provided a situation awareness reference for the EPs. The digital read-outs provided precise, numerical reference data.

The ADI also roughly mimicked that which is currently in use (Fig. 5). This display provided ownship 3-axis LVLH attitude on the pitch/roll/yaw "eight-ball." Around the periphery of the "eight-ball," the body-axis roll rate, pitch rate and yaw rates are shown by a white arrow, measured against a $\pm 1.0 \mathrm{deg} / \mathrm{sec}$ scale. Finally, yellow pitch, roll, and yaw "vernier" deviation needles were also displayed. The functionality of these needles changed, depending upon the experimental control law, as detailed in later sections.

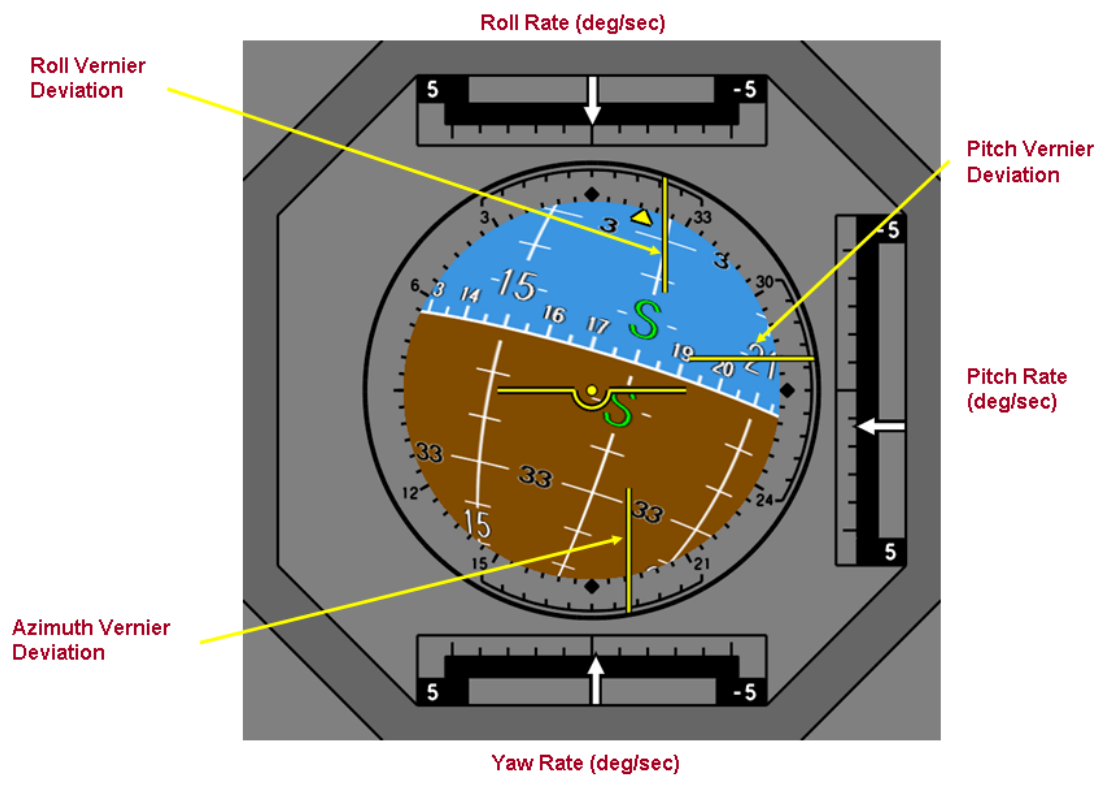

Figure 5. Attitude Direction Indicator

The Centerline Camera display simulated a camera view forward of the nose of the simulated Orion vehicle (Fig. 6). The simulated centerline camera was located $6 \mathrm{ft}$ forward of the vehicles' CG. This display provides a direct view of the ISS docking port stand-off alignment cross and target background. The simulated docking point was 10 $\mathrm{ft}$ forward of the CG. In conjunction with the camera grid overlay, this information was used by the EPs to assess ownship docking position and attitude with respect to the ISS docking port. ${ }^{16}$ 

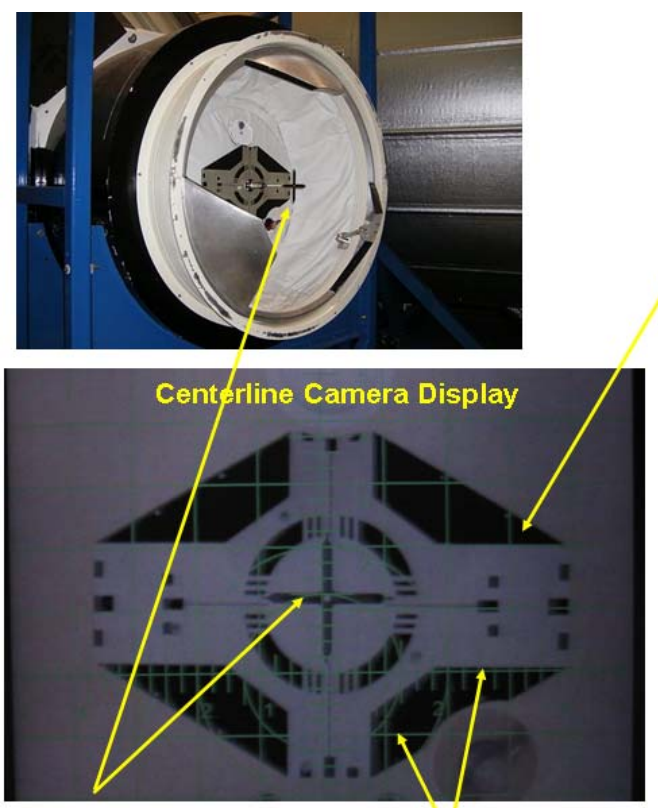

Stand-Off Cross

Camera Grid

Background

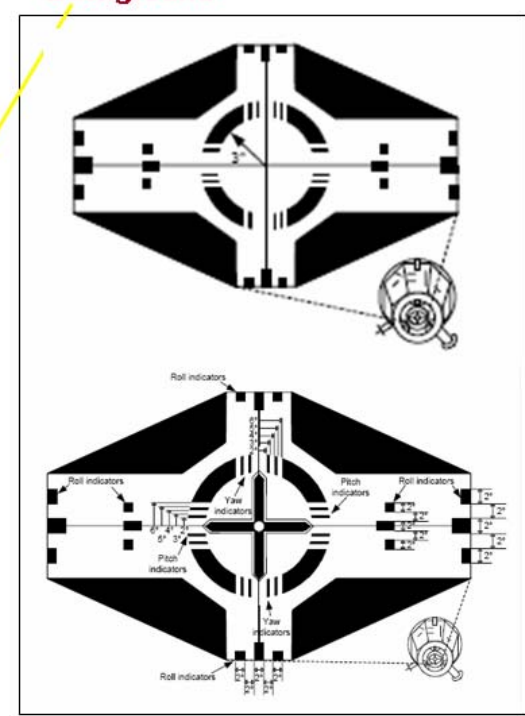

Figure 6. Centerline Docking Camera Display

\section{Experiment}

The primary experimental goal was to evaluate the effect of the RCS design on rotational (attitude) control handling qualities during proximity operations and docking in Earth orbit. Secondarily, piloting task influences were evaluated.

\section{A. Rotation and Translation Control Laws}

Two rotational control law types were implemented: a) Rate Command/Attitude Hold (RCAH) and b) Pulse Mode. These modes are depicted in the schematic diagram of Fig. 7.

In RCAH mode, when the pilot exceeded the RHC deadband (15\% stick deflection) in an axis, a discrete rate of $0.05 \mathrm{deg} / \mathrm{sec}$ was commanded in that rotational axis. Once the control was returned within the deadband, the vehicle rates relative to the LVLH frame were arrested and a new attitude reference was set. A phase plane RCAH architecture for rate and attitude limits and deadbands was implemented, following Shuttle flight control system architecture design philosophy. ${ }^{18}$ The RCAH rate limit in all axes was $0.10 \mathrm{deg} / \mathrm{sec}$. The RCAH attitude deadband in all axes was \pm 0.25 degrees. The phase plane switching curves were defined (see Reference 19) as the square of the attitude-rate error divided by twice the thruster acceleration, where the thruster accelerations were set as constants for this test, using $0.00365 \mathrm{rad} / \mathrm{sec}^{2}$ for roll, $0.00661 \mathrm{rad} / \mathrm{sec}^{2}$ for pitch, and $0.00766 \mathrm{rad} / \mathrm{sec}^{2}$ for yaw.

The vernier deflection needles on the ADI (yellow needles in Fig. 5) directly showed the attitude error in relation to the deadband limits $( \pm 0.25$ degrees, corresponding to full scale deflection) when in RCAH mode.

If the controller exceeded $90 \%$ of full-scale deflection, the control law would enter into an "acceleration" mode, whereby continuous firing of a rotational jet pair was commanded until the controller returned below the $90 \%$ fullscale value and then, a free drift mode was entered (i.e., no jet firings). Once the controller was returned to the neutral position, a new attitude reference was then set after LVLH rates were nulled by opposing jet pair firings.

In Pulse mode, when the pilot exceeded the RHC deadband in an axis (15\% stick deflection), a discrete pulse was commanded in that rotational axis. The pulse size was experimentally varied. Another pulse could only be generated if the control was returned to neutral position and then placed out of the controller deadband again. If the controller exceeded $90 \%$ of full-scale deflection, the control law would enter into the "acceleration" mode, described in the preceding paragraph.

The vernier deflection needles on the ADI (yellow needles in Fig. 5) indicate \pm 1 deg of attitude from the desired LVLH desired docking attitude when Pulse mode was selected. This provided a vernier attitude indication from desired docking attitude. 
Translational control was always set to "direct mode" whereby THC commands continually fired RCS jet pairs to effect translation in the commanded axis for as long as the THC was held out of detent (i.e., THC Deadband). The THC-Pulse mode was not used in the experiment.

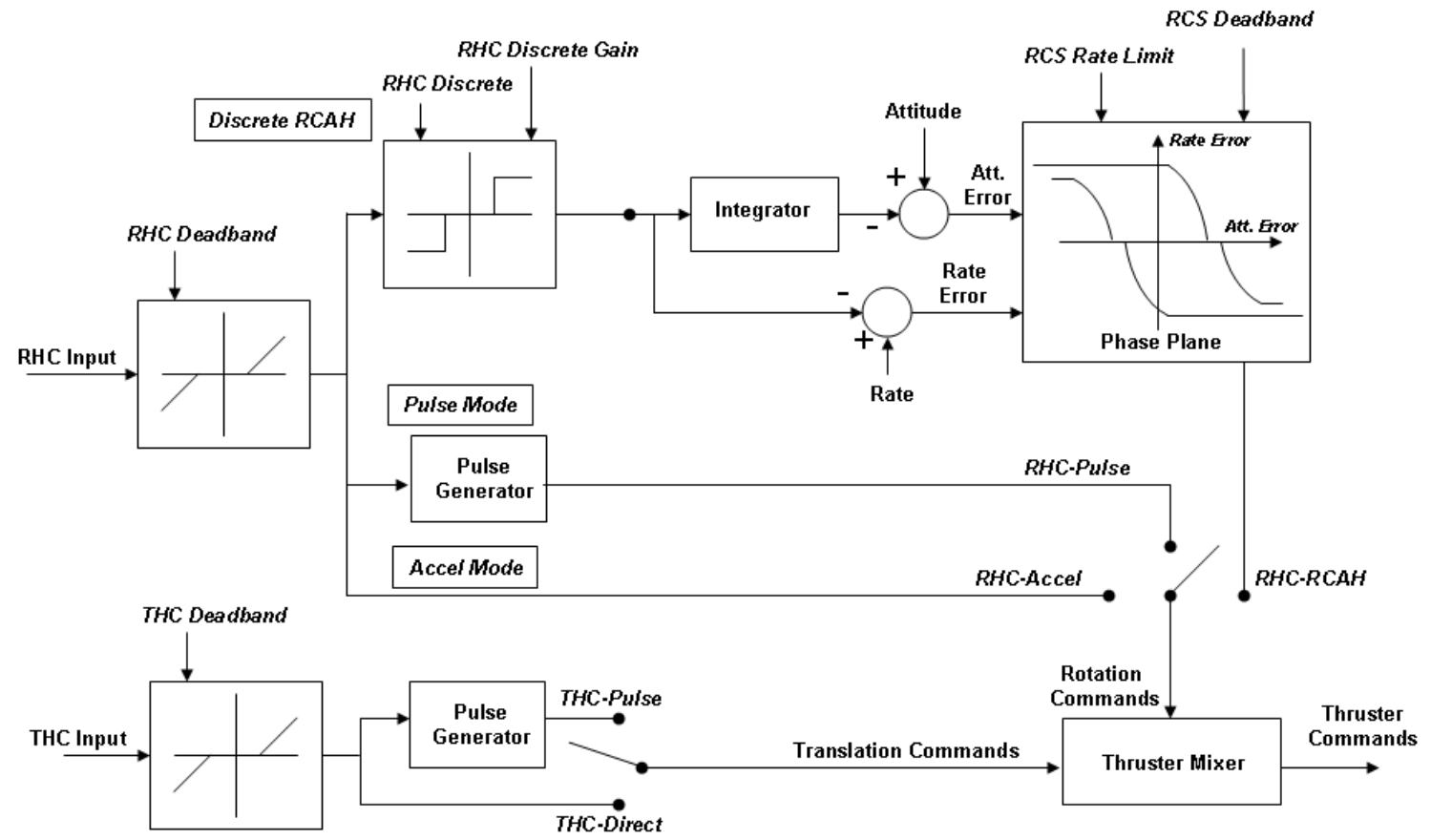

Note that italics denote GUi-Selectabie Options

Figure 7. Control Law Schematic Diagram

\section{B. Test Configurations - Pulse Mode and Coupling}

Using the generic spacecraft model, a $2 \times 2 \times 3$ experiment matrix was established to evaluate the interaction of RCS jet size (12.5 lbf and $50 \mathrm{lbf}$ jets, fired in pairs), rotational pulse size ("coarse" and "fine," using RCS pulse widths of $0.10 \mathrm{deg} / \mathrm{sec}$ and $0.04 \mathrm{deg} / \mathrm{sec}$, respectively), and translation-into-rotation-coupling by manipulation of RCS location (forward/centered/aft) relative to CG. The objective was to evaluate if handling qualities are affected by the degree of thruster-induced coupling (translation-into-rotation) and the magnitude of the jet firing and its duration. The configuration summary is shown in Table I below. (Note that the RCS thruster configurations in Table I are identified by the total thrust magnitude simulated (i.e., $100 \mathrm{lbf}$ and $25 \mathrm{lbf}$ ). Also, the equivalent nomenclature of " $2.0 \mathrm{x}$ " and " $0.5 \mathrm{x}$ " is used which is in relation to the configurations shown in the next section.

The vehicle was symmetric in shape and mass distribution with a 99 inch annular radius. The vehicle mass was 1059.4 slugs, with a roll inertia $\left(\mathrm{I}_{\mathrm{xx}}\right)$ of 32,263 slug- $\mathrm{ft}^{2}$ and pitch and yaw inertias $\left(\mathrm{I}_{\mathrm{yy}}\right.$ and $\left.\mathrm{I}_{\mathrm{zz}}\right)$ of 50,000 slug- $\mathrm{ft}^{2}$. Cross-products of inertia were zero.

Table 1: Pulse Mode Configurations (Generic Spacecraft Model)

\begin{tabular}{|ll|c|c|c|c|}
\hline & RCS Thruster & \multicolumn{2}{|c|}{$2.0 \mathrm{x}$ Thrust (100 lbf) } & \multicolumn{2}{|c|}{$0.5 \mathrm{x}$ Thrust (25 lbf) } \\
\cline { 2 - 6 } & RCS Pulse Width & $0.10 \mathrm{deg} / \mathrm{sec}$ & $0.04 \mathrm{deg} / \mathrm{sec}$ & $0.10 \mathrm{deg} / \mathrm{sec}$ & $0.04 \mathrm{deg} / \mathrm{sec}$ \\
\hline \hline \multirow{2}{*}{$\begin{array}{l}\text { Coupling } \\
\text { Direction }\end{array}$} & Adverse & 1 & 2 & 3 & 4 \\
\cline { 2 - 6 } & Neutral & 5 & 6 & 7 & 8 \\
\cline { 2 - 6 } & Proverse & 9 & 10 & 11 & 12 \\
\hline
\end{tabular}


The jet sizes span commercially available thruster values. ${ }^{4}$ The rotational pulse sizes were scaled to produce consistent levels of rotational acceleration, analogous to minimum thruster on-time effects. Finally, three RCS jet longitudinal locations were simulated as described in the following.

The first case placed the CG and RCS jet longitudinal location at the same x-axis (body) position so translational RCS jet firings did not introduce spacecraft rotation changes (i.e., uncoupled or "neutral coupling"). The second and third cases placed the RCS jets 38 inches forward or aft of the CG x-axis (body) position so translational RCS jet pair firings either introduced "adverse" or "proverse" spacecraft rotation changes, respectively. (The terminology "proverse" or "adverse" was taken from the aeronautics domain where roll-yaw coupling can produce adverse or proverse yaw during roll maneuvers.) For a configuration with adverse coupling, a command to translate the vehicle upwards would also cause a pitch rotation in the nose-down direction, causing the target image on the centerline camera to move up, seemingly counter to the translation command. Conversely, in a case with proverse coupling, a command to translate upwards would effect a pitch rotation in the nose-up direction, seemingly additive to the translation command. This coupling effect also occurred in the lateral translation/yaw rotational axes as well. This is shown notionally in Fig. 8.

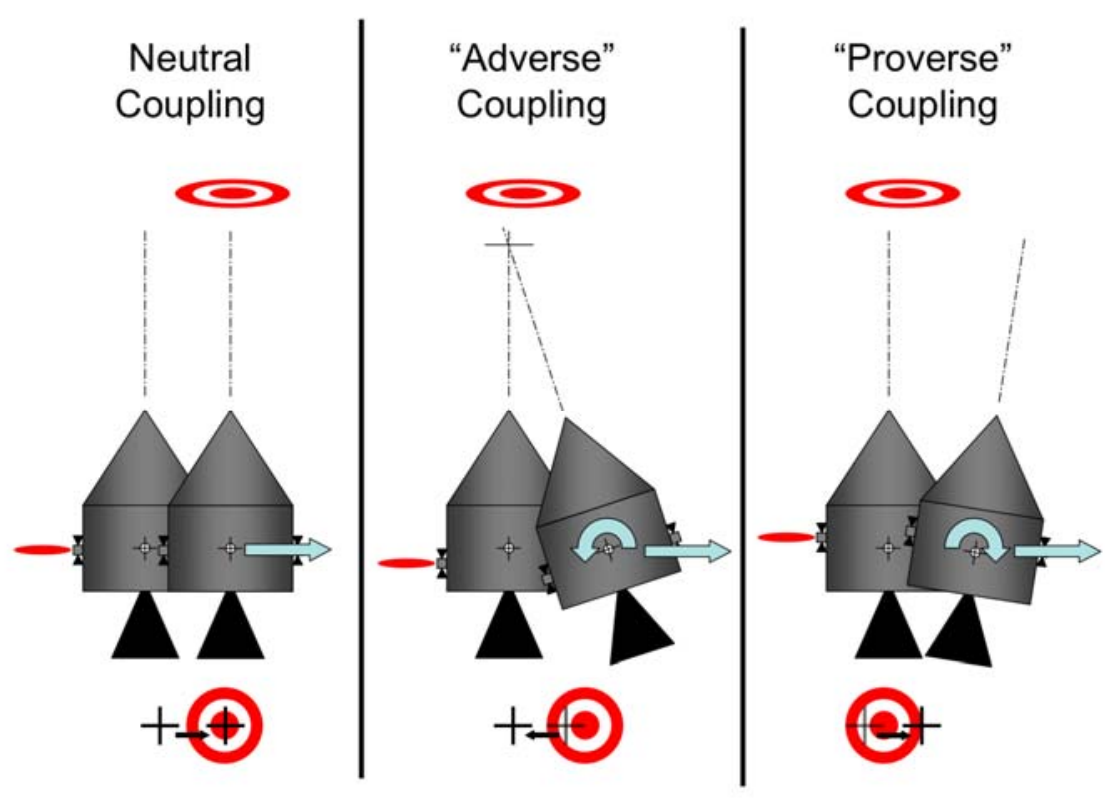

Figure 8. Depiction of Neutral, Adverse And Proverse Translation-Into-Rotation Coupling

For the Generic model, rotational and translational commands fired thruster pairs. Rotational control commands fired RCS jet combinations to achieve rotation without translation. No coupling occurred with forward/aft translations.

The experiment design created the following experimental parameters:

- Translational Control Power: For the 2.0x thrust configurations (100 lbf thrust) configurations, the translational control power (acceleration) in each axis was $0.0944 \mathrm{ft} / \mathrm{sec}^{2}$, compared to $0.0236 \mathrm{ft} / \mathrm{sec}^{2}$ for the $0.5 \mathrm{x}$ thrust configuration ( $25 \mathrm{lbf}$ thrust).

- Pitch/Yaw Control Power: For the 2.0x thrust configurations (100 lbf thrust) configurations, the rotational control power (acceleration) in pitch and yaw was $0.945 \mathrm{deg} / \mathrm{sec}^{2}$, compared to $0.236 \mathrm{deg} / \mathrm{sec}^{2}$ for the $0.5 \mathrm{x}$ thrust configuration ( $25 \mathrm{lbf}$ thrust).

- Translation-to-Rotation Coupling: For the 2.0x thrust configurations (100 lbf thrust) configurations, the adverse/proverse coupling configurations created $0.363 \mathrm{deg} / \mathrm{sec}^{2}$ of rotational acceleration due to translational jet firings, compared to $0.091 \mathrm{deg} / \mathrm{sec}^{2}$ for the $0.5 \mathrm{x}$ thrust configuration ( $25 \mathrm{lbf}$ thrust). (The neutral cases produced no rotational-translational coupling and the adverse and proverse configurations produced identical coupling magnitudes, but with signs reversed.) 


\section{Test Configurations - Rotational Control Mode}

Another portion of the test used the ARC-CEV spacecraft model to overlap and extend the complementary ARC spacecraft handling qualities test. ${ }^{14}$ A $2 \times 3$ experiment matrix was established using two RCS control modes (RCAH or Pulse) and 3 RCS thruster magnitudes (Nominal, 0.5 times nominal, and 2.0 times nominal). The objective was to evaluate if handling qualities for a highly-coupled vehicle configuration are affected by the rotational control law type (RCAH or Pulse) and the RCS jet size.

Unlike the generic model, rotational control commands fired RCS jet combinations that created rotation as well as translation and vice versa. RCS location changes were not used in this part of the test.

The experiment design created the following experimental parameters:

- Translational Control Power: For the 1.0x (nominal) thrust configurations, the translational control power (acceleration) was $0.0395 \mathrm{ft} / \mathrm{sec}^{2}$ in lateral (y-axis) translation and $0.0538 \mathrm{ft} / \mathrm{sec}^{2}$ in vertical (zaxis) translation. The $2.0 \mathrm{x}$ and $0.5 \mathrm{x}$ thruster configurations exhibit twice and half the control power, respectively.

- $\quad$ Pitch/Yaw Control Power: For the 1.0x (nominal) thrust configurations, the rotational control power (acceleration) was $0.379 \mathrm{deg} / \mathrm{sec}^{2}$ for yaw and $0.434 \mathrm{deg} / \mathrm{sec}^{2}$ for pitch. The $2.0 \mathrm{x}$ and $0.5 \mathrm{x}$ thruster configurations exhibit twice and half the control power, respectively.

- Translation-to-Rotation Coupling: For the 1.0x (nominal) thrust configurations, the yaw coupling due to lateral (y-axis) translational jet firings created $0.269 \mathrm{deg} / \mathrm{sec}^{2}$ of rotational acceleration and the pitch coupling due to vertical (z-axis) translational jet firings created $0.191 \mathrm{deg} / \mathrm{sec}^{2}$ of rotational acceleration. The $2.0 \mathrm{x}$ and $0.5 \mathrm{x}$ thruster configurations exhibit twice and half the rotational coupling, respectively.

The rotational-coupling due to translational inputs was always adverse.

\section{Evaluation Tasks}

Simulated proximity operations and docking were flown using + V-bar approaches only, in relation to an LVLH coordinate system relative to the ISS. The vehicle initial V-bar position was either $+10 \mathrm{ft},+20 \mathrm{ft}$, or $+50 \mathrm{ft}$ from the docking port. Offsets of $\pm 3 \mathrm{ft}$ in R-bar and Y-bar were also introduced on each data run. Further, offsets of 2.5 degrees in attitude (pitch, roll, and yaw) were also included for the Pulse mode evaluations. In every case, the vehicle had zero body angular rates relative to LVLH.

A desired axial closure rate was asked to be flown on each task. Nominally, this closure rate was $0.1 \mathrm{fps}$ toward the docking target. The $0.1 \mathrm{fps}$ closure rate is essentially the nominal Shuttle docking closure rate. Additionally, a higher 0.5 fps closure rate was used to evaluate its influence on handling qualities. Although not tested in this experiment, during Gemini and Apollo, the nominal closure rate for docking was $1.0 \mathrm{fps}$. At the start of each run, the vehicle's initial conditions were set at the desired closure rate to the docking target.

No performance standards were enforced during the approach phase of the task with the exception of the axial closure rate. This performance standard was established to ensure task consistency. Without an approach closure rate performance standard, this degree of freedom might allow the EPs to slow or stop their approach to the docking port, if they felt that more time might improve their performance. This would effectively change the piloting task and introduce an unconstrained variable into the test.

The desired and adequate performance standards are shown in Table 2. These parameters only applied to the docking itself, with the exception of axial closure rate as discussed above.

Table 2: Desired and Adequate Task Performance Standards

\begin{tabular}{|l|l|l|}
\hline & Desired Performance & Adequate Performance \\
\hline \hline Radial Offset & $\pm 1.5 \mathrm{in}$ & \pm 1.5 to $\pm 3.2 \mathrm{in}$ \\
\hline Roll/Pitch/Yaw Angle & $\pm 2.0 \mathrm{deg}$ & \pm 2.0 to $\pm 3.0 \mathrm{deg}$ \\
\hline Axial Closure Rate $(0.1 \mathrm{fps})$ & 0.075 to $0.125 \mathrm{fps}$ & 0 to $0.075 \mathrm{fps}$ OR 0.125 to $0.15 \mathrm{fps}$ \\
\hline \multicolumn{1}{r|}{$(0.5 \mathrm{fps})$} & 0.375 to $0.625 \mathrm{fps}$ & 0 to $0.375 \mathrm{fps}$ OR 0.625 to $0.75 \mathrm{fps}$ \\
\hline Radial (Linear) Rate & $\pm 0.0325 \mathrm{fps}$ & \pm 0.0325 to $\pm 0.1125 \mathrm{fps}$ \\
\hline Roll/Pitch/Yaw (Angular) Rate & $\pm 0.05 \mathrm{deg} / \mathrm{sec}$ & \pm 0.05 to $\pm 0.15 \mathrm{deg} / \mathrm{sec}$ \\
\hline
\end{tabular}




\section{E. Experiment Protocol}

Each EP was given an initial briefing before the start of the experiment, outlining the experimental objectives and an overview of the simulation and the test procedures. At least two hours of training in the simulator was conducted to ensure familiarity with the tasks, the displays, the controllers, the control modes, and the subjective data measures. Data collection followed thereafter. Data collection was nominally limited to 1 hour periods, with 15 minute breaks between, to mitigate fatigue.

All configurations were flown "blind" to the EPs. The EP was only briefed on the rotational control modes (RCAH or Pulse Mode), the desired closure rate, and the initial LVLH position.

For each configuration, the EPs first flew one approach and docking for practice/familiarity, followed by a minimum of two runs for "data." The EP had the option for a third run if they felt that the two runs exhibited very different characteristics that potentially hampered their handling qualities assessment.

Following the tasks, the EPs assigned a Pilot Rating (PR) using the Cooper-Harper rating scale. ${ }^{1}$ Pilot comments were then given, generally prompted via a comment card. Finally, NASA Task Load Index (TLX) workload ratings ${ }^{20}$ were given.

Engineering unit and video data was recorded on all runs. Pilot audio comments were digitally recorded and transcribed.

\section{Results}

\section{A. Test Subjects}

Ten EPs flew as subjects. Three populations of EPs were used. The first population consisted of current and former Astronauts who have flown as commanders on Space Shuttle docking missions. These subjects have significant and invaluable training and real-world experience in proximity operations and docking. The second population consisted of current and former Astronauts who have not flown as commanders on docking missions but nonetheless, have significant training in spacecraft proximity operations and docking. Finally, the third population consisted of experimental test pilots who do not have significant training in spacecraft proximity operations and docking, but are experienced in handling qualities evaluations. All subjects were graduated as pilots from the Air Force Test Pilot School or Naval Test Pilot School and were experienced in aircraft handling qualities evaluations.

\section{B. Evaluation Data}

Not every evaluation pilot was available for enough time to support the entire test matrix; thus, configurations were prioritized to ensure that they were evaluated by the majority of the EPs.

One unfortunate consequence of this prioritization scheme was that the proverse-coupled Pulse mode evaluations, being lower in priority, were flown by fewer evaluation pilots and flown after the completion of the neutral- and adverse-coupled Pulse mode evaluations. This had an influence in the data as described below.

Repeat evaluations were flown as possible to check for training/learning effects, especially in regard to the potential bias due to run prioritization. Also, repeat evaluations were used on occasion to "validate" evaluations where the ratings and comments may have deviated from the perceived norm.

\section{Pulse Mode and Coupling}

In Table 3, the Cooper-Harper PRs for the Pulse mode evaluations are listed by EP and configuration number. The configuration characteristics and configuration number (i.e., "vehicle") are given in Table 1.

The PRs are plotted in Fig. 9 using a "bubble chart" where the marker size (i.e., the "bubble" area) is proportional to the number of occurrences of a given PR.

These data and the attendant pilot comments show some clear trends.

First, rotational Pulse mode meant that the EPs were flying a "6 degree-of-freedom (6 DOF)" task. The EPs used the ADI for rotational attitude and attitude rate control and the Centerline Camera display for translational docking alignment. This 6 DOF task was complicated by the fact that the centerline camera display reflected changes in both relative attitude and translation. The EPs had to null initial condition attitude offsets to get to the desired docking attitude while simultaneously translating the vehicle onto the approach centerline and toward the docking target for docking. Even for those Astronauts with considerable experience with this type of maneuver and control mode, considerable training was necessary to get the necessary task information into their scan pattern and to properly execute the controller inputs to achieve desired docking performance. Learning curves were observed in the data, as discussed below, and they were also apparent to almost every EP. 
Table 3: Cooper-Harper Pilot Ratings - Generic Spacecraft

\begin{tabular}{|c|c|c|c|c|c|c|c|c|c|c|}
\hline \multirow{2}{*}{$\begin{array}{l}\text { Veh. } \\
\text { No. }\end{array}$} & \multicolumn{10}{|c|}{ Pilot } \\
\hline & 1 & 2 & 3 & 4 & 5 & 6 & 7 & 8 & 9 & 10 \\
\hline 1 & 5,5 & 6 & 5 & 10,9 & 7 & 9 & 8 & 5 & 6 & 4 \\
\hline 2 & 10 & 4 & 4 & 4 & 5 & 8 & 9,6 & 3 & 5 & 7 \\
\hline 3 & 4.5 & 5 & 4 & 5 & 5 & 8 & 8 & 3 & 5 & 7,9 \\
\hline 4 & 7 & 7 & 5 & 4 & 5 & 7 & 5 & 3 & 4,5 & 4 \\
\hline 5 & 4.5 & 4.5 & 4 & 7 & 5 & 7 & 5 & 4 & 5 & 5 \\
\hline 6 & 4.5 & 4,3 & 4 & 4 & 3 & 4 & 3 & 3 & 3 & 3 \\
\hline 7 & 4 & 4 & 4 & 4 & 5 & 3 & 3 & 3 & 4,3 & 2 \\
\hline 8 & 3 & 4 & 4 & 4 & 5 & 2 & 2 & 3 & 4 & 3 \\
\hline 9 & 5.5 & 6 & 4 & 9 & 5 & & 6 & & 6 & \\
\hline 10 & 4 & $4.5,4.5$ & 5 & 4 & 5 & & 4 & & 5 & 4 \\
\hline 11 & 4 & 5 & 4 & 4 & 4 & & 4 & & 6 & 4 \\
\hline 12 & 4 & 4.5 & 4 & 5 & 4 & 4 & 5 & 4 & 5 & 3 \\
\hline
\end{tabular}

Second, even without translation-to-rotation coupling, rotational Pulse mode control laws exhibit borderline Level 1 - Level 2 flying qualities. In general, with neutral coupling, the EPs were able to get desired performance but often the workload associated with controlling and monitoring the translational rates to perform the docking task while attaining the desired docking attitude alignment from an offset initial condition, created workload and pilot compensation which was beyond "minimal." Only $38 \%$ of the evaluations were rated as being satisfactory without improvement. The flying qualities data are essentially independent of pulse size and thruster size with the exception of the 2.0x thrust multiplier and large pulse size $(0.10)$ as discussed later in this section.

Third, coupling clearly degrades flying qualities. Very few Level 1 ratings were given to any of the adverse- or proverse-coupled configurations. The majority of ratings were Level 2, with numerous Level 3 ratings as well. The primary issue, again, was pilot workload because each translational control input had to be counter-corrected with rotational inputs. The problem was acute in controlling the vehicle very close to docking. If translational corrections were needed in close, the proper rotational input was immediately needed to put the vehicle back into the proper attitude for docking. Without nulling the rotational rates, an incorrect sense of translation was shown on the centerline camera display. Or worse, if an incorrect rotational correction was made, the problems quickly exacerbated and poor docking performance would result.

Fourth, in the presence of translational-rotational coupling, the larger control power (2.0x thrust multiplier) and coarse pulse size $(0.10 \mathrm{deg} / \mathrm{sec})$ dramatically degraded flying qualities. The larger control power created the greatest magnitude of coupling which was particularly problematic near docking.

The coarse pulse size did not allow precise control of the attitude rates. One very experienced astronaut, on the first evaluation of this configuration gave a PR of 10, and on the repeat run after considerable experience with other Pulse configurations, still gave the configuration a PR of 9, noting that "you're borderline losing control and intense compensation (is) required." Even without coupling, the 2.0x thrust multiplier condition and the coarse pulse width $(0.10 \mathrm{deg} / \mathrm{sec})$ created solid Level 2 handling qualities and, in two cases, even Level 3 ratings - "Performance was attainable but ... you couldn't have that up in space. One mistake and you'd have an accident “

The docking task was driven by relatively tight performance tolerances (see Table 2). These standards were based on data relative to the anticipated docking mechanisms for Constellation and those anticipated for the COTS platforms. ${ }^{21}$ The most significant parameters that typically drove whether desired or adequate performance was met for the Pulse mode evaluations were that the attitude rates had to be less than $\pm 0.05 \mathrm{deg} / \mathrm{sec}$ for desired performance. The pilot comment data indicated that the critical flying qualities determinants were the pilot workload and compensation (both mental and physical) to control the 6 DOF Pulse mode configurations for successful docking. As shown in Fig. 10, the workload ratings (average TLX data) closely tracked the PR data. 


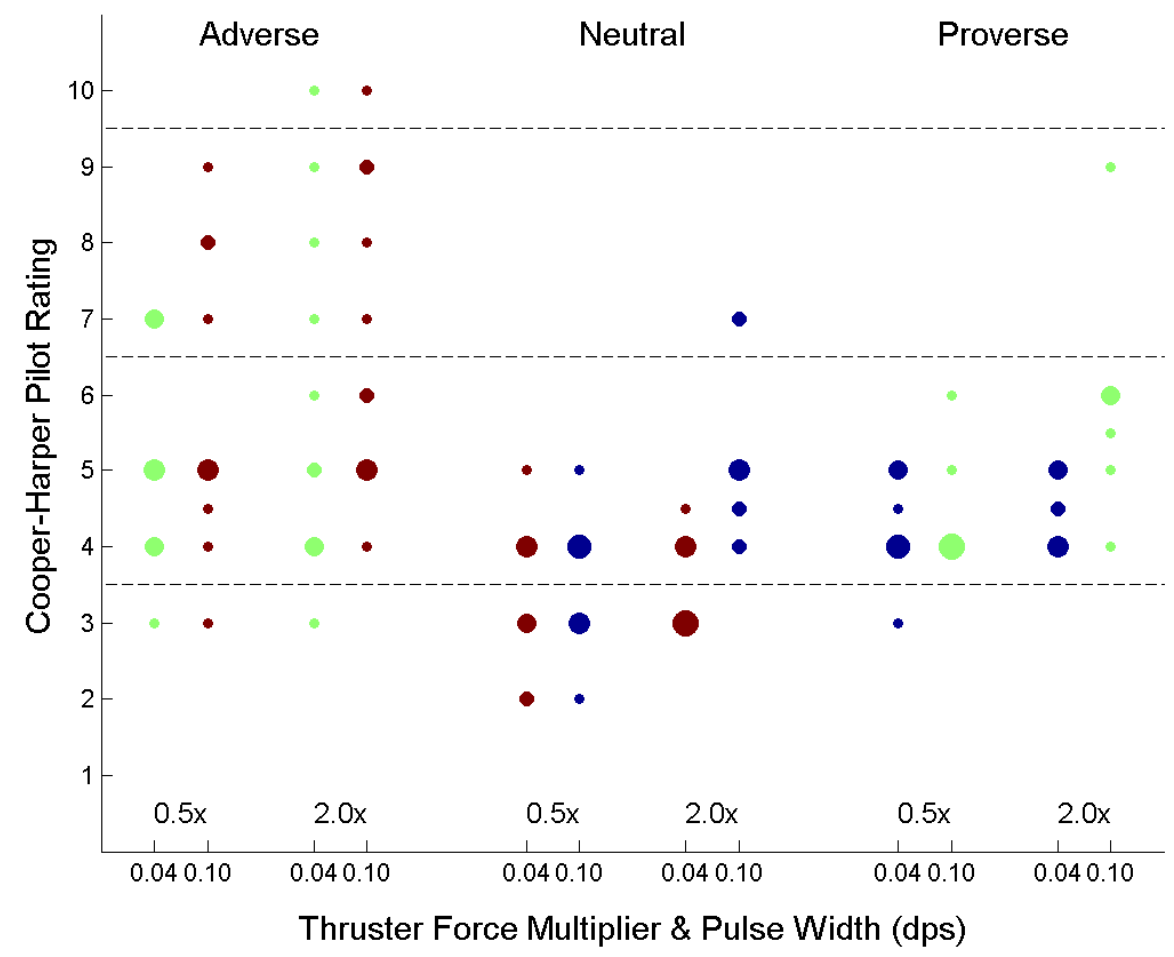

Figure 9. Pilot Rating Data for Pulse Mode / Coupling Evaluations

Finally, training was an influence. The prioritization scheme used in the experiment design inadvertently biased the adverse-coupled configuration evaluations into the "learning curve." Post-flight de-brief of the EPs acknowledged the learning curves. It was also evident in the much higher PRs for these configurations. The postflight de-brief comments noted that the proverse- or adverse-coupling direction was essentially immaterial. It was noted by most, however several EPs didn't recognize the directional difference.

The post-flight comments and observations indicated that the key parameters in the training (and the evaluations) were: 1) understanding the effect of coupling and particularly, its influence in the centerline camera display. The adverse-coupled configurations could induce too much translation because the adverse rotation makes the docking target almost stationary on the centerline displays (especially when the distance to the target was close to the instantaneous center of rotation). For proverse-coupling, it was the opposite effect; and, 2) learning the scan pattern to absorb the displayed information and putting the controls into action. Once up-to-speed, Pulse mode performance became much better. Nonetheless, the adverse- and proverse-coupled configurations, while exhibiting better performance after training, are still not Level 1 overall. The vehicle response characteristics and workload associated with their control was rarely satisfactory without improvement. But as evident by the comparison between the proverse- and adverse-coupled cases, after training, the task could be done to adequate standards, however workload was still high. More importantly, there was concern voiced on several occasions that, even after training, the response characteristics and the resultant error margins for these configurations, particularly for high control power and coarse pulse sizes, could lead to accidents and incidents that were unacceptable (Level 3 ratings). 


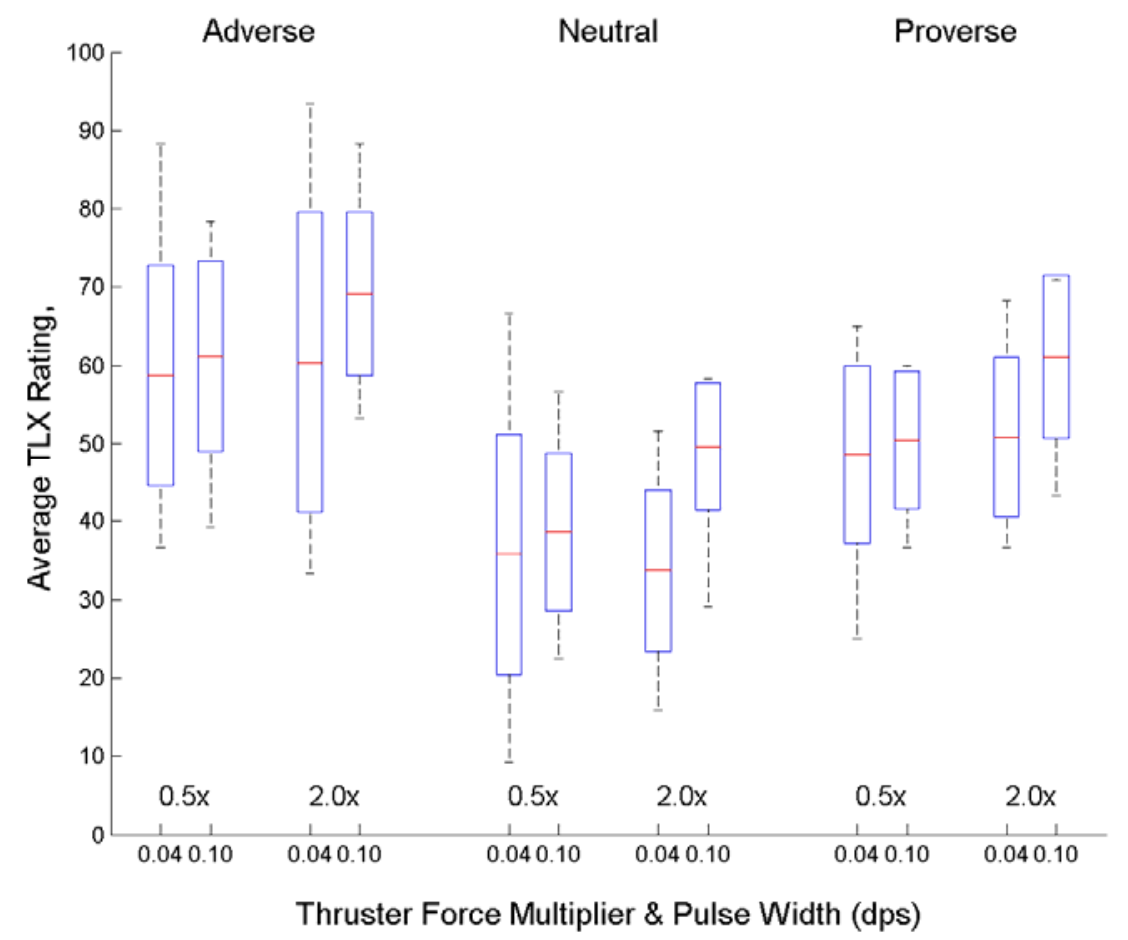

Figure 10. Average TLX (Horizontal Line), +/- 1 Standard Deviation (Box) and Maximum/Minimum Ratings for Pulse Mode / Coupling Evaluations

In terms of docking performance (Fig. 11), an Analysis of Variance (ANOVA) test, using the main factor of translation-to-rotation coupling $(\mathrm{F}(2,244)=17.84, \mathrm{p}<0.001)$ was statistically significant for radial position offset at docking. Post-hoc tests (Student's T-test using $\alpha=0.05$ ) showed that docking performance with the adverse coupled configuration was significantly worse (mean=1.02 inch) than either the neutral- (mean=0.49 inch) or proversecoupled (mean=0.53 inch) configurations, which were not significantly different from each other. On average, the adverse coupled configurations still exhibited docking within desired error tolerance for radial position $(<1.5$ inch radial error). The absence of statistically significant differences between the neutral- and proverse-coupled configurations suggest that, with training, the levels of coupling flown here would not be expected to impact docking task performance. Similar performance levels and trends were shown for the other docking parameters.

As one would expect, the pilot control corrections needed to fly the Pulse mode configurations were proportional to the flying qualities data and were directly reflected by the fuel expenditure to do the task. An ANOVA test, using the main factors of translation-to-rotation coupling factors $(\mathrm{F}(2,244)=9.7434, \mathrm{p}<0.001)$ was statistically significant for fuel usage. Post-hoc tests (Student's T-test using $\alpha=0.05$ ) showed that docking performance with the adverse coupled configuration was significantly worse (mean=4.74 lbm) than either the neutral- $(\mathrm{mean}=3.02 \mathrm{lbm})$ or proverse-coupled $($ mean $=3.47 \mathrm{lbm})$ configurations, which were not significantly different from each other. 


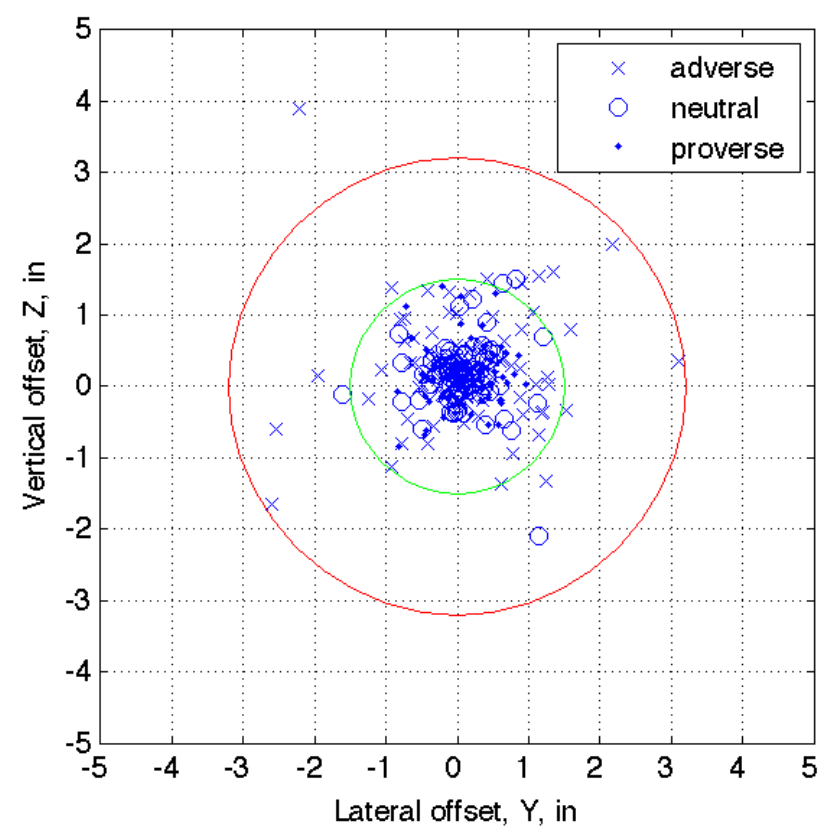

Fig. 11. Docking Position (Vertical and Horizontal) for Pulse Mode Configurations

\section{Rotational Control Mode Evaluations}

In Table 4, the Cooper-Harper PRs comparing RCAH and Pulse mode control laws for the ARC-CEV configuration are listed by EP. This configuration uses a slanted/skewed RCS thruster arrangement, thus, "guaranteeing" coupling between axes, and between rotation and translation and vice versa. For this same configuration, the RCS jet sizes were varied by twice and half nominal, as described in Section IV above.

The PRs are plotted in Fig. 12 using a "bubble chart" where the marker size (i.e., the "bubbles") is proportional to the number of evaluations for a given PR.

Table 4: Cooper-Harper Pilot Ratings - Cooper-Harper Pilot Ratings - ARC-CEV Spacecraft

\begin{tabular}{|c|c|c|c|c|c|c|c|c|c|c|c|}
\hline \multirow[b]{2}{*}{$A R C-C E V$} & \multirow[b]{2}{*}{ Mode } & \multicolumn{10}{|c|}{ Pilot } \\
\hline & & 1 & 2 & 3 & 4 & 5 & 6 & 7 & 8 & 9 & 10 \\
\hline \multirow[t]{2}{*}{ 1.0x Thruster } & $\mathrm{RCAH}$ & 4.5 & 4.5 & 3 & 4 & 2 & 8 & 7 & 6 & 5 & 5 \\
\hline & Pulse & 7 & 4 & 4 & 5 & 5 & 8 & 8 & 5 & 5 & 7 \\
\hline \multirow[t]{2}{*}{$0.5 \mathrm{x}$ Thruster } & $\mathrm{RCAH}$ & 5 & 4 & - & 5 & 4 & - & - & - & 6 & - \\
\hline & Pulse & 5 & 4 & - & 4 & 10 & - & - & - & 5 & - \\
\hline \multirow[t]{2}{*}{ 2x Thruster } & $\mathrm{RCAH}$ & 7 & 4 & - & 6 & 4 & - & - & - & 5 & - \\
\hline & Pulse & 4.5 & 6 & - & 5 & 8 & - & - & - & 6 & - \\
\hline
\end{tabular}




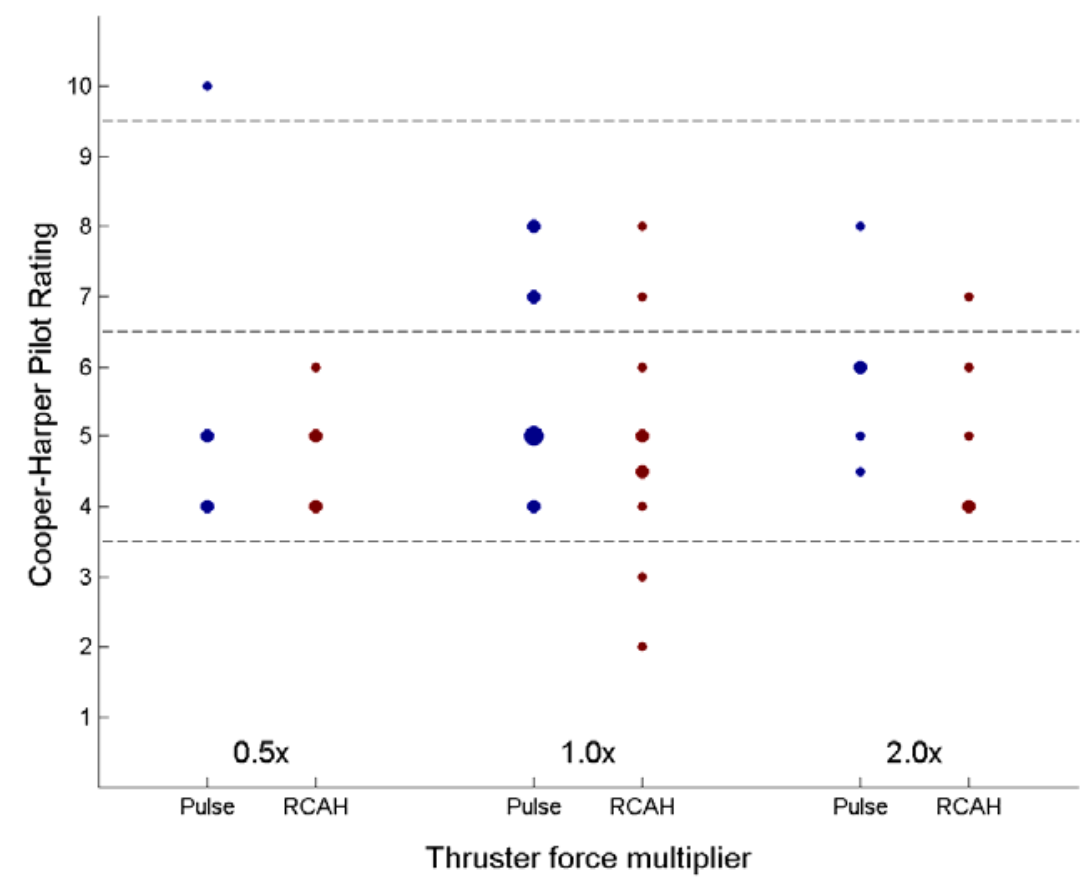

Fig. 12. Pilot Rating Data for RCAH and Pulse Mode Evaluations - ARC/CEV Vehicle

In general, these data show that RCAH improves the flying qualities of the spacecraft for docking. For the nominal RCS jet size (1.0x) configuration, three of the 10 EPs noted a flying qualities level improvement. Nonetheless, the overall improvement due to the RCAH control law was not dramatic. This result was seemingly counter-intuitive. One would have expected that the more sophisticated RCAH control law would significantly improve flying qualities since the control law reduces the piloting task from a 6 DOF maneuver where the pilot must control both rotational and translational modes, to a 3 DOF maneuver where the pilot only has to control translation (while the automatic RCAH controls rotation).

The data shows that RCAH does indeed reduce the pilot's control requirements; however, flying qualities are not improved because the workload and performance remains essentially the same. The RCAH control law reduced the physical workload component by eliminating the need for the pilot to control rotation but the RCAH added workload in the form of mental and control compensation to adjust translational control firings in anticipation of or as reaction to RCAH rotational deadband firings from the RCAH control law. The results were consistent across RCS jet size.

The RCAH used a constant \pm 0.25 deg deadband. With the skewed/slanted RCS jet alignment of the ARC-CEV configuration, once an attitude deadband was hit, the RCS firings produced a very noticeable response. The response was clearly evident in the centerline camera display near docking and could noticeably impact the docking task performance "score." As one EP said, the "vehicle is not going to go out of control because it's going to hold attitude plus or minus the deadbands, but I don't feel like I'm really in control." The EP's tried several techniques to compensate for the deadbands. In either case, they used the centerline camera for translation position and the deadband needles on the ADI to estimate when a jet firing would occur.

Most often, the EPs tried to back-off from achieving docking "perfection" (i.e., achieving zero radial docking error with little or no attitude or translation rate) and accepted some error while still being within desired performance limits. By eliminating translational control inputs close to docking, the likelihood of a rotational deadband firing could be minimized. This technique could work, but it produced frustration because of the EP's innate desire for perfection.

More typically, the EPs would compensate by flying an offset position away from the docking cross, which was "sized" based on their estimate of when a deadband firing would occur and its resultant effect on the position. In essence, they planned for the deadband firing.

The last technique was that the EPs would just use translational control firings to immediately counter any deadband rotational firings. This latter technique could be problematic because translational firings close to docking 
could cause the docking performance levels to exceed the desired performance criteria for translational or rotational rates.

This variation in control technique and the influence of the deadband firings created a large variation in the EP's opinion of the flying qualities. The ratings ranged from a PR of 2 to a PR of 8 for the same configuration based on each EP's individual assessment of the compensation required to fly these configurations.

The average TLX data, shown in Fig. 13, shows little change in workload between the RCAH and pulse mode control law for the ARC-CEV configuration. These data substantiate the minimal improvement in flying qualities with the control law change. Note that the average TLX workload rating for each configuration is in the 50 to 65 range, compared to the 30 to 40 range for the uncoupled pulse mode ratings in Fig. 9. This difference illustrates that a more sophisticated control law (i.e., the RCAH) may not necessarily be the best approach for good flying qualities in the spacecraft docking task. The key parameter for the EPs was the coupling response to control inputs, and just restricting the attitude excursion using an RCAH control law was not, in essence, a "cure." It just bounded the problem.

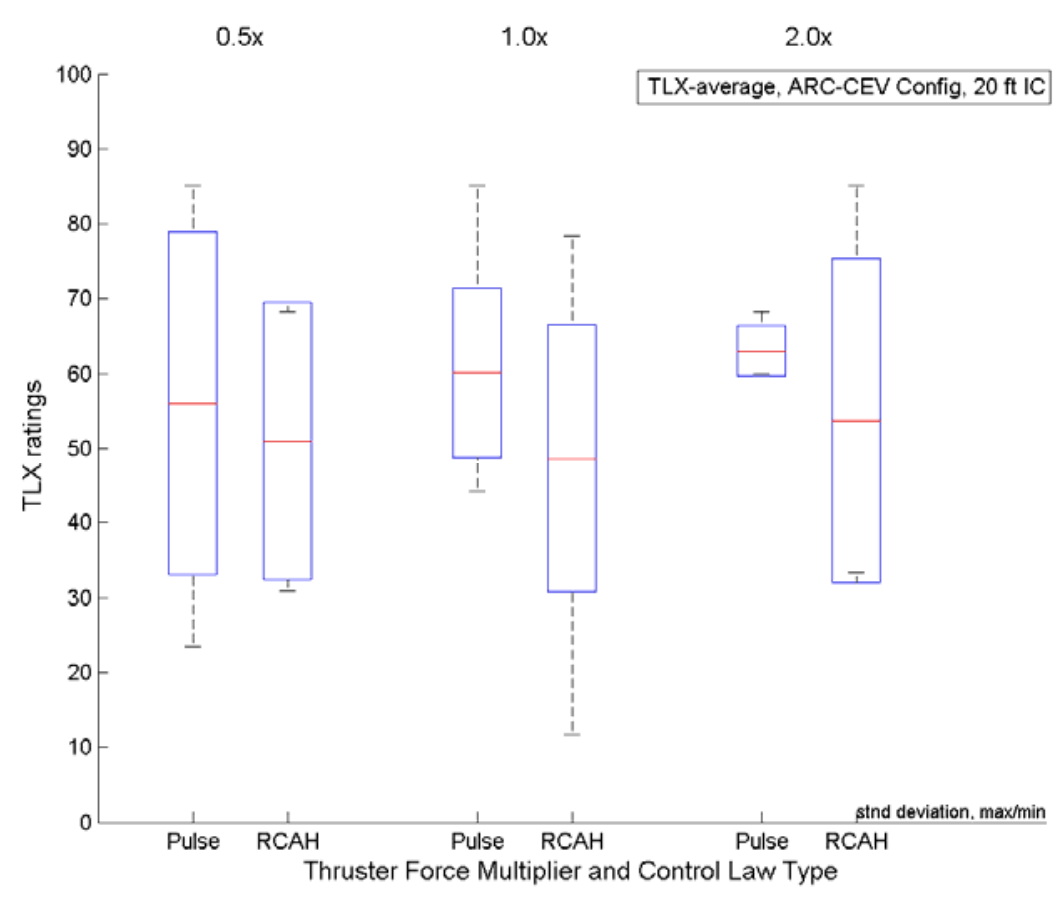

Figure 13. Average TLX (Horizontal Line), +/- 1 Standard Deviation (Box) and Maximum/Minimum Ratings for Pulse Mode / RCAH Evaluations

\section{E. Docking Task Effect}

In Table 5, the Cooper-Harper PRs comparing RCAH and Pulse mode control laws and the influence of the docking task for the ARC-CEV configuration are listed by EP. This part of the experiment again used the slanted/skewed RCS thruster configured vehicle.

Three tasks were flown. The first task started at a $10 \mathrm{ft}$ initial condition (IC) from docking with a closure rate of 0.1 fps. Only RCAH control law evaluations were used for this task. The $20 \mathrm{ft}$ IC and closure rate of $-0.1 \mathrm{fps}$ represented the nominal task. These data are reported above. Finally, a $50 \mathrm{ft}$ IC was used with a closure rate of -0.5 fps. With this IC and closure rate, the docking is completed in the same amount of time as the $10 \mathrm{ft}$ IC. Only half of the EPs flew comparative Pulse Mode control law evaluations for this task.

The PRs are plotted in Fig. 14 using a "bubble chart" where the marker size (i.e., the "bubbles") is proportional to the number of evaluations for a given PR. 
Table 5: Cooper-Harper Pilot Ratings - ARC-CEV Spacecraft Task Influence

\begin{tabular}{|c|c|c|c|c|c|c|c|c|c|c|c|}
\hline \multirow[b]{2}{*}{$A R C-C E V$} & \multirow[b]{2}{*}{ Mode } & \multicolumn{10}{|c|}{ Pilot } \\
\hline & & 1 & 2 & 3 & 4 & 5 & 6 & 7 & 8 & 9 & 10 \\
\hline \multirow[t]{2}{*}{$10 \mathrm{ft} \mathrm{IC}$} & RCAH & 4.5 & 4 & 3 & 5,5 & 2 & 7,7 & $9,7.5$ & 4 & 5 & 4,6 \\
\hline & Pulse & - & - & - & - & - & - & - & - & - & - \\
\hline \multirow[t]{2}{*}{$20 \mathrm{ft} \mathrm{IC}$} & $\mathrm{RCAH}$ & 4.5 & 4.5 & 3 & 4 & 2 & 8 & 7 & 6 & 5 & 5 \\
\hline & Pulse & 7 & 4 & 4 & 5 & 5 & 8 & 8 & 5 & 5 & 7 \\
\hline \multirow[t]{2}{*}{$50 \mathrm{ft} \mathrm{IC}$} & $\mathrm{RCAH}$ & 4.5 & 4 & - & 7 & 6 & 6 & 7 & 4 & 5 & 7 \\
\hline & Pulse & 5 & 7 & - & 10 & - & 10 & - & - & 10 & - \\
\hline
\end{tabular}

The data and comments support that the $20 \mathrm{ft}$ IC was regarded as the easiest of the three tasks, but not dramatically so, at least for the RCAH configurations. The ratings between the $10 \mathrm{ft}$ and $20 \mathrm{ft} \mathrm{IC}$ are almost identical and still span the Level 1 and Level 3 regions due primarily to pilot interpretation differences in the workload and acceptability of the RCAH deadband firings.

With the $50 \mathrm{ft}$ IC and higher closure rate, the RCAH configuration is solidly rated as Level 2, borderline Level 3 ratings. No Level 1 ratings were given. The higher closure rate obviously changed the character of the task. As one EP expressed, "The problem is, at these high rates of closure, you don't have enough time to be messing around with all these kind of control inputs that you have to do." Added another: "it's just a timing thing. I was looking ahead trying to plan ahead, which I don't want to have to do that much planning ahead during a docking evolution, to see when is it going to hit the deadband... That's too much, that puts it in the major deficiency category for me."

For the higher closure rate, $50 \mathrm{ft}$ IC condition, the Pulse Mode evaluation of the highly-coupled ARC-CEV configuration produced near unanimous Level 3 ratings, including 3 PRs of 10. The high closure rate increased the time pressure for coordination between translational and rotational coupling. If coordination mistakes were committed (i.e., rotation in the wrong direction), the results could be catastrophic. Unfortunately, no data were collected for the $10 \mathrm{ft}$ IC in Pulse Mode because of the lack of time.

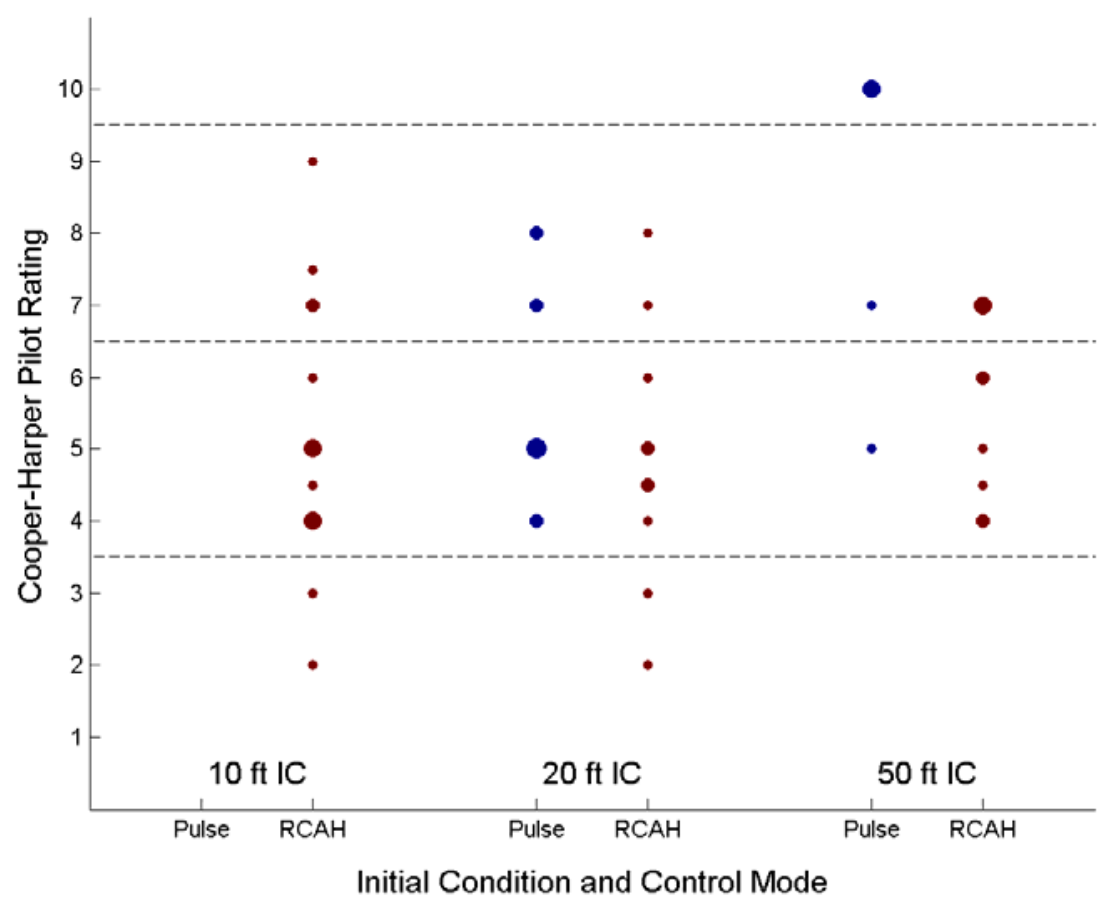

Fig. 14. Pilot Rating Data for RCAH / Pulse Mode Evaluations With Task Changes - ARC/CEV Vehicle 


\section{Concluding Remarks}

Handling qualities embody "those qualities or characteristics of an aircraft that govern the ease and precision with which a pilot is able to perform the tasks required in support of an aircraft role." ${ }^{11}$ These same qualities are as critical, if not more so, in the operation of spacecraft.

In this first experiment, the effects of Reaction Control System design characteristics and rotational control laws were evaluated during proximity operations and docking. Also, the influence of piloting task demands resulting from closure rate changes was assessed.

The pilot-in-the-loop simulation results showed that significantly different spacecraft handling qualities result from the design and location of the RCS. In particular, cross-coupling between translational and rotational control significantly affected handling qualities as reflected by Cooper-Harper Pilot Ratings.

This influence is masked - but only slightly - by an attitude control system. While rotational control augmentation using rotational RCAH can reduce the workload (principally, physical workload) created by crosscoupling, the handling qualities are not significantly improved. The attitude deadbands of the RCAH eliminated the need for the pilot to control spacecraft attitude, but the deadbands still significantly influenced the task performance and significantly drove up pilot compensation.

The effect of task demands was also evident in the findings. Using a higher closure rate reduced the time that the EP had to make corrections in attitude or position for docking. As a result, the rotational Pulse mode configurations with coupling produced Level 3 flying qualities. The RCAH configurations fared slightly better, but they were no better than Level 2.

The data strongly suggests that control coupling is the primary determinant to good spacecraft handling qualities for docking. A suggested guideline for Pulse mode flying qualities was offered by one EP:

- The optimum coupling level is no coupling.

- The borderline for acceptable coupling is determined by the number of pulses in rotation required to offset one pulse in translation. If more than one rotation pulse is required to compensate for one translation pulse, that's unacceptable.

- A much better configuration exists if one pulse or less in rotation is required for two pulses in translation.

- The rotational pulse size is dictated by the desired and adequate docking rates. The rotational pulse size should be no greater than $50 \%$ of the desired rotational rates allowable at docking.

Further refinement of handing qualities guidelines is planned in future experiments.

\section{Acknowledgments}

The authors wish to thank the simulation staffs of NASA Langley and Ames Research Center for their support, as well as retired astronaut Karol J. "Bo" Bobko for his assistance and advice.

\section{References}

${ }^{1}$ Cooper, G.E., and Harper, R.P. Jr., "Use of Pilot Rating in the Evaluation of Aircraft Handling Qualities," NASA TN D5153, April 1969.

${ }^{2}$ Harper, R P, Jr. and Cooper, G E., "Handling Qualities And Pilot Evaluation," AIAA Journal of Guidance, Control, and Dynamics, Vol. 9, Sept.-Oct. 1986, pp. 515-529.

${ }^{3}$ D'Souza, C.D., and Hanak, F.C., and Spehar, P., "Orion Rendezvous, Proximity Operations, and Docking Design and Analysis," AIAA Guidance, Navigation, and Control Conference and Exhibit, Paper 2007-6683, Hilton Head, SC, 20-23 August 2007.

${ }^{4}$ Jackson, M. and Gonzalez, R., "Orion Orbit Reaction Control Assessment," AIAA Guidance, Navigation, and Control Conference and Exhibit, Paper 2007-6684, Hilton Head, SC, 20-23 August 2007.

${ }^{5}$ Riley, D.R.; Jaquet, B.M.; Bardusch, R.E.; and Deal, P.L., "A Study of Gemini-Agena Docking Using a Fixed-Base Simulator Employing a Closed-Circuit Television System,” NASA TN D-3112, 1965.

${ }^{6}$ Riley, D.R.; Jaquet, B.M.; and Cobb, J.B., "Effect of Target Angular Oscillations on Pilot-Controlled Gemini-Agena Docking," NASA TN D-3403, 1966.

${ }^{7}$ Long, E.R., Jr.; Pennington, J.E.; and Deal, P.L., "Remote Pilot-Controlled Docking With Television," NASA TN D-3044, October 1965.

${ }^{8}$ Pennington, J.E.; Hatch, H.G., Jr.; Long, E.R.; and Cobb, J.B., "Visual Aspects of a Full-Size Pilot-Controlled Simulation of the Gemini-Agena Docking,” NASA TN D-2632, 1965.

9Jaquet, B.M.; and Riley, D.R., "An Evaluation of Gemini Hand Controllers and Instruments for Docking,” NASA TM X1066, 1965.

${ }^{10}$ Riley, D.R., Jaquet, B.M., Pennington, J.E., and Brissenden, R.F., “Comparison Of Results Of Two Simulations Employing Full-Size Visual Cues For Pilot-Controlled Gemini-Agena Docking,” NASA TN D-3687, Nov. 1966. 
${ }^{11}$ Hatch, H.G., Jr.; Riley, D.R.; Cobb, J.B., "Simulating Gemini-Agena Docking,” Astronautics and. Aeronautics, Vol. 2, No. 11, Nov. 1964, pp. 74-81.

${ }^{12}$ Cooper, G.E., "Understanding and Interpreting Pilot Opinion," Aeronautical Engineering Review, Vol. 16, No. 3, March 1957, pp. 47-51.

${ }^{13}$ Goodman, J.L., "History of Space Shuttle Rendezvous and Proximity Operations," Journal Of Spacecraft And Rockets, Vol. 43, No. 5, September-October 2006.

${ }^{14}$ Mueller, E., Bilimoria, K., and Frost, C., "Initial Handling Qualities Evaluation for Spacecraft Docking in Low Earth Orbit," AIAA Guidance, Navigation and Control Conference, AIAA-2008-6832, Honolulu, HI, August, 2008.

${ }^{15}$ Smith, R.M., "A Description of the Cockpit Motion Facility and the Research Flight Deck Simulator," AIAA Modeling and Simulation Technologies Conference, AIAA-2000-4174, Denver, CO, Aug. 14-17, 2000

${ }^{16}$ National Aeronautics and Space Administration, "Rendezvous Crew Training Handbook," USA006064, Rev. C, Oct 2005.

${ }^{17}$ Clark, F.D., Spehar, P.T., Brazzel, J.P. Jr., and Hinkel, H.D., "Laser-Based Relative Navigation and Guidance for Space Shuttle Proximity Operations," Advances in the Astronautical Sciences, Guidance and Control, Vol. 113, 2003, pp. 171-186.

${ }^{18}$ Nakano, M.M, and Willms, R.L., "Space Shuttle On-Orbit Flight Control System," AIAA Guidance and Control Conference, Paper 1982-1576, San Diego, CA, August 9-11, 1982.

${ }^{19}$ Bryson, A.E. Jr., Control of Spacecraft and Aircraft. Princeton University Press, Princeton, NJ, 1994.

${ }^{20}$ Hart, S.G. \& Staveland, L.E. (1988). Development of NASA-TLX (Task Load Index): results of empirical and theoretical research. In P.A. Hancock \& N. Meshkati (Eds.), Human Mental Workload (pp. 139-183). Amsterdam: North-Holland.

${ }^{21}$ AIAA, "Guide for the Serviceable Spacecraft Grasping/Berthing/Docking Interfaces," AIAA G-056-1992., American Institute for Aeronautics and Astronautics, New York, New York, 1992. 